\title{
MASS MEDIA DISCOURSE: REPRESENTATION OF THE WAR CONCEPT IN THE CONTEXT OF "9/11" CULTURE TIME
}

\author{
Tatyana V. Ukhova \\ Siberian State University of Science and Techlogies, Krasnoyarsk, Russian Federation \\ Svetlana G. Efa \\ Siberian State University of Science and Techlogies, Krasnoyarsk, Russian Federation
}

\begin{abstract}
In the present article, which is based on the modern English-language publicistic writing, specific features of mass media discourse development in terms of culture time "Before 9/11" and "After 9/11" are revealed. The authors show the influence of a certain cultural context on the formation of concept clusters and subcultures leading to WAR concept transformation in certain period. Using the methods of analyzing the word definitions representing the concept, contextual analysis, analysis of conceptual metaphors, discourse and culture time, the authors make conclusion that in the context of culture time "After 9/11" mass media discourse reflects direct protest against leveling the concept of war and sport discourse dramatization: perception of mass media discourse in general is determined by the participation of "protesting" journalists in the group categorization; discourse as a semiotic medium can be characterized by its overall intentionality - the mind is focused on the route of evil, on fighting terrorism and revenge; cumulative metaphorical proposition of the text is represented by means of protest metaphors SPORT IS NOT WAR, WORDS ARE NOT WEAPONS, LANGUAGE IS NOT BATTLEFIELD, WAR IS NOT SPORT. It has been proved that their ontological realization (SOMETHING IS NOT WAR) can change the studied concept in the new culture time "After 9/11".

Key words: discourse, WAR concept, culture time, metaphor, sphere of concepts, archetype, semiosis, subculture.

Citation. Ukhova T.V., Efa S.G. Mass Media Discourse: Representation of the WAR Concept in the Context of "9/11" Culture Time. Vestnik Volgogradskogo gosudarstvennogo universiteta. Seriya 2, Yazykoznanie [Science Journal of Volgograd State University. Linguistics], 2017, vol. 16, no. 3, pp. 153-162. (in Russian). DOI: https:// doi.org/10.15688/jvolsu2.2017.3.15
\end{abstract}

УДК 81’42:070

Дата поступления статьи: 24.04.2017

ББК 81.055 .515 Дата принятия статьи: 26.05.2017

\section{ДИСКУРС СМИ: РЕПРЕЗЕНТАЦИЯ КОНЦЕПТА WАR В КОНТЕКСТЕ ВРЕМЕНИ КУЛЬТУРЫ «9/11»}

\section{Татьяна Витальевна Ухова}

Сибирский государственный университет науки и технологий имени академика М.Ф. Решетнева, г. Красноярск, Российская Федерация

\section{Светлана Георгиевна Эфа}

Сибирский государственный университет науки и технологий имени академика М.Ф. Решетнева, г. Красноярск, Российская Федерация

Аннотация. В статье на материале современной англоязычной публицистики выявлены особенности развития массмедийного дискурса в условиях времени культуры «Before 9/11» и «After 9/11», показано влияние определенного контекста культуры на формирование концептосферы и субкультуры, приводящее к 
трансформации концепта WAR в условиях этого времени. С использованием методов анализа словарных дефиниций, репрезентирующих концепт, контекстуального анализа, анализа концептуальных метафор, дискурса и времени культуры установлено, что в контексте времени культуры «After 9/11» дискурс СМИ отражает прямой протест против нивелирования сущности понятия войны и драматизации спортивного дискурса: восприятие дискурса СМИ в целом определяется участием «протестующих» журналистов в групповой категоризации; дискурс как семиотическое пространство характеризуется общей интенциональностью направленностью сознания на источник зла, на борьбу с терроризмом и на отмщение; совокупная метафорическая пропозиция текста реализуется посредством протестных метафор SPORT IS NOT WAR, WORDS ARE NOT WEAPONS, LANGUAGE IS NOT BATTLEFIELD, WAR IS NOT SPORT. Доказано, что их онтологизация (SOMETHING IS NOT WAR) приводит к изменению рассматриваемого концепта в новом времени культуры «After 9/11».

Ключевые слова: дискурс, концепт WAR, время культуры, метафора, концептосфера, архетип, семиозис, субкультура.

Цитирование. Ухова Т. В., Эфа С. Г. Дискурс СМИ: репрезентация концепта WAR в контексте времени культуры «9/11» // Вестник Волгоградского государственного университета. Серия 2, Языкознание. - 2017. T. 16, № 3. - C. 153-162. - DOI: https://doi.org/10.15688/jvolsu2.2017.3.15

1

Интерес к изучению феномена войны как концепта определен несколькими факторами. Вопервых, война является неотъемлемой данностью социально-исторического бытия, «коллективного бессознательного». Во-вторых, нестабильность социально-политической и экономической ситуации в мире характеризуется постоянным столкновением ценностей, интересов и целей индивидов, компаний и государств. В-третьих, как пишет Г.Г. Почепцов, реальные войны, не прекращающиеся в современном обществе, подвергаются глубокому анализу как с идеологической, политической, исторической, экономической, психологической, так и с филологической точек зрения, что дает основания для более глубокого проникновения в природу человеческого сознания и может быть полезным для поиска реальных способов урегулирования конфликтов [Почепцов, 1990]. В-четвертых, в процессе дискурсивной деятельности социума война и ее вербальные воплощения в различных дискурсах становятся объектом оценки, что находит отражение в метафорическом осмыслении данного феномена.

Предметом настоящего исследования является концепт WAR в англоязычном лингвокультурном сознании. В работе принято определение концепта, предложенное В.И. Карасиком и Г.Г. Слышкиным, которые понимают лингвокультурный концепт как условную ментальную единицу, используемую в комплексном изучении языка, сознания и культуры [Карасик, Слышкин, 2005, с. 75].
Объектом исследования является языковое представление концепта WAR, объективируемое в дискурсе СМИ, в контексте времени культуры до и после 9/11, 2001.

Цель работы - проследить эволюцию концепта WAR в континууме определенной лингвокультуры, выявив метафорические модели экспликации концепта во времени культуры «After 9/11», определив особенности семиосферы и концептосферы WAR во времени культуры «After 9/11», описав наиболее релевантные аспекты понимания WAR современным англоязычным социумом на основе массмедийного дискурса с точки зрения интенциональности и характера семиосферы. С учетом специфики поставленных задач спектр выбранных методов исследования включает: анализ словарных дефиниций, репрезентирующих концепт; концептуальный анализ, в который вошли контекстуальный анализ, анализ концептуальных метафор, анализ дискурса, анализ времени культуры.

Материалом изучения послужили тексты современных печатных масс-медиа, а также электронные версии современных английских журналов и газет. Общий объем текстов составил более 9000 страниц (в данной статье подробно рассмотрены три типовые публикации). В качестве дополнительного источника привлекались данные толковых словарей.

Научная новизна работы заключается в том, что впервые осуществлено исследование концепта WAR во времени культуры «After 9/11», в котором онтологизировалась протестная метафopa SPORT IS NOT WAR. 
T.В. Ухова, С.Г. Эфа. Дискурс СМИ: репрезентация концепта WAR в контексте времени культуры «9/11»

\section{2}

Понятийная составляющая концепта WAR реализуется в наборе значений ключевого имени war, объективирующего ядро исследуемого концепта. С опорой на данные 11 толковых словарей современного английского языка (в том числе электронные издания последних лет) ${ }^{1}$ были отобраны восемь часто приводимых значений (перечислим их в порядке следования в словарных статьях, выделяя в толкованиях значимые для понимания концепта WAR компоненты): A state of open, armed, often prolonged conflict carried on between nations, states, parties $(1,2)$; Fighting between two or more opposing groups or countries that involves the use of armed forces and usually continues for a long time (3); A hostile attack, invasion, assault (4); An active struggle between competing entities (5, 6); A concerted effort or campaign to end something that is injurious (7); A situation in which two people or groups of people fight, argue, or are extremely unpleasant to each other (8).

Понятийные компоненты концепта WAR, отраженные в системе значений его имени (существительного war), образуют зону пересечения этого концепта с концептом CONTEST (COMPETITION), поскольку существительное contest (имя соответствующего концепта) может выражать значение «а struggle for victory between opposing forces or interests». Следовательно, в этом случае WAR и CONTEST концептуализируют тождественные сущности, содержательный минимум которых можно определить посредством дефиниции ключевого слова struggle - «a fight, а war, an attempt to do smth. that takes a lot of effort during a long period of time». Отметим, однако, что в большинстве словарей в качестве основного значения существительного contest приводится «а competition, esp. one in which people's skill in a particular activity or sport is tested / a formal game or match in which two or more people, teams, etc., compete and attempt to win», что свидетельствует о наличии в структуре концепта CONTEST признаков, свидетельствующих об игровом характере концептуализируемой им деятельности. Что касается контекстной реализации, то в основном данный концепт эксплицируется не в военном, а в политическом, экономическом (бизнес), спортивном дискурсах. Концепт CONTEST (COMPETITION) актуализирует идею противостояния участников «войны» в качестве соперников, целью которых является победа, а также желание прославиться, добиться успеха (как материального, так и морального), что часто становится причиной современных экономических и политических конфликтов.

\section{3}

Любой концепт находится в постоянном движении и претерпевает изменения. Благодаря диффузному характеру структуры концептов в них отражаются все изменения среды: социальные, исторические и культурные. Согласно Ю.М. Лотману, культура - семиотизированный внешний мир. Время культуры есть структура семиозиса, отличающая данный период времени с точки зрения общей интенциональности социума и его ментальности [Лотман, 2000, с. 259]. Событие, главенствующее в рамках времени какой-либо культуры, определяет все знаковые доминанты семиосферы и генерирует тексты культуры. Соответственно, новое событие заставляет переосмысливать реальность в горизонте иной интенциональности социума.

Феноменом культуры является и дискурс, поскольку, как считает В.И. Карасик, важнейшие его характеристики - ценностные. В коллективном сознании языковых личностей могут быть выделены ценностные доминанты соответствующей культуры [Карасик, 2002, с. 271]. В новом времени культуры образуются новые ценностные константы, определяющие «непрорефлексированное, эмоционально окрашенное мировидение», и формируется новый, разделяемый социумом горизонт интенциональности, фокусирующий «мировидение» на объекте действительности [Корнилов, 2003].

Анализируя языковой материал, отражающий изменения в отношении жителей США к феномену войны, мы проследили изменения в ценностной картине мира североамериканского социума, рассматривая концепт WAR c позиции времени культуры. В рамках данной категории дискурс становится знаковым отражением структуры сознания и социально- 
сти той или иной эпохи. Структура дискурса соответствует структуре определенного исторического типа сознания и общества, а развитие дискурса происходит относительно некой доминирующей ценности в определенное время культуры. Следовательно, дискурсы становятся вербальным выражением времени культуры. Дискурсивная деятельность концентрируется вокруг ключевых концептов (знаков), которые являются семантическими или прагматическими доминантами, отличающими одно время культуры от другого. Однако «дискурс не может исчерпывать все время культуры, а только вербально или письменно выраженную его часть» [Лотман, 1999, с. 165].

События 11 сентября 2001 г. в США стали проводником новых идеологических смыслов и послужили тому, что носители североамериканской культуры начали сомневаться в оправданности использования языка войны в немилитарных сферах, противостоять вербальной агрессии, характерной для языка политики, экономики, спорта. Новое событие заставило переосмыслить реальность с учетом новой интенциональности социума.

Чтобы наглядно представить время культуры «After 9/11», целесообразно коротко описать время культуры 90-х гг., то есть время «Before 9/11». Оно характеризовалось экономической стабильностью («Клинтоновский рай»): стабильные цены, дешевые жилье и нефть, условия, в которых можно больше работать и соответственно больше зарабатывать (об отражении такой ситуации в дискурсе см.: [Плотникова, 1997]). Семиосферу, детерминированную этим временем культуры, С.Н. Плотникова определяет как стабильность, характеризуемую благополучием. В концептосфере актуализировались концепты: HAPPINESS, OPTIMISM, STABILITY, SECURITY и т. п.

В противоположном направлении развивалось время культуры «After 9/11». Теракты 11 сентября были объявлены актом войны. Американцы сами признают, что «это странный тип войны, в ней нет линии фронта, нет концентрации войск, она ведется как бы в тени, против ускользающего противника, без ясной направленности действий, без представления о том, что эта война должна закончиться» [Уткин, 2003, c. 383]. Характерными знаками этого времени стали «угроза», «агрессия», «терроризм», «за- щита свободы». Следовательно, в концептосфеpe актуализировались концепты WAR, TERRORISM, FEAR, DANGER, AGGRESSION, SADDAM, NUCLEAR WEAPONS, VICTIMS, FREEDOM, RESPONSIBILITY и т. п.

\section{4}

Важно заметить, что внутри времени культуры могут выявляться субкультуры, организованные в общей для данной культуры системе координат. Субкультуры могут выражать свою причастность к общему времени культуры, а также выражать несогласие с ним: «наш» и «их» мир внутри «нашего» [Малинович, 2003, c. 4]. В субкультуре вырабатывается единая идеология, осуществляется поиск общего смысла. Культура и субкультура являются частью единого «контекста культуры», поэтому результаты исследований субкультур можно рассматривать как сведения об общественной ситуации и людях, приверженных определенным культурным ценностям.

Дискурсом-репрезентантом в данной работе является дискурс субкультуры журналистов, центральным дискурсообразующим событием - 9/11, дискурсообразующим концептом - WAR, дискурсообразующей протестной метафорой - SPORT IS NOT WAR, WAR IS NOT SPORT. Возникновение подобных протестных метафор может быть объяснено тем фактом, что архетипически война - это полюс смерти, а не игры, то есть метафоры, как и авторы дискурсов, протестуют против того, что фактически стираются грани между полюсами культуры (см.: [Ухова, 2010]).

Тема войны, а именно способа борьбы с терроризмом, после событий 9/11 стала доминантой в дискурсе СМИ. Основными участниками дискурса стали журналисты, объединенные одной целью - опровергнуть или пересмотреть концептуальные метафоры, онтологизирующие концепт WAR в таких видах мирной деятельности, как спорт, бизнес, политика. Создалось своего рода «дискурсивное сообщество» людей [Swales, 1990], противостоящих вербальным войнам в различных видах мирной деятельности. Дж. Суэйлс определяет дискурсивные сообщества как социориторические группы, объединенные общ- 
T.В. Ухова, С.Г. Эфа. Дискурс СМИ: репрезентация концепта WAR в контексте времени культуры «9/11»

ностью коммуникативных целей. Члены такого сообщества могут быть отдалены друг от друга, принадлежать к разным социальным и этническим группам, но они очень хорошо информированы в избранной сфере общения [Swales, 1990, p. 22].

Ценностные ориентации рассматриваемого дискурсивного сообщества отражаются дискурсообразующими метафорами, то есть метафорами, используемыми в аналитических текстах. А.М. Каплуненко вводит понятие «экспертное дискурсивное сообщество» [Каплуненко, 2007, с. 115]. В пространстве дискурса экспертного сообщества появляется «полифония частных точек зрения» (термин М.М. Бахтина). Специфические интересы экспертного сообщества становятся целевой установкой дискурса. Значимость частной точки зрения поднимается здесь до статуса частной доминантной ценности, замкнутой на самой себе.

Далее подробно рассмотрим три типовые аналитические статьи в аспектах влияния времени культуры и знаковых событий на развитие дискурса, а также динамики концепта WAR.

\section{5}

5.1. Статья «Fighting words: The war over language» Дж. Хутена (см.: Hooten) представляется нам одной из наиболее репрезентативных. Итак, локализация метафоры LANGUAGE IS WAR в заголовке устанавливает горизонт интерпретации сообщения. Как известно, заголовок является доминантой, репрезентирующей основную идею сообщения [Dijk, 1985, p. 53]. Пресуппозиция такова, что любая тема в современном обществе может быть описана языком войны, в фокусе сознания автора находится вопрос о том, могут ли вербальные конфликты перерасти в реальные войны и как противостоять вербальной агрессии. Таким образом, заголовок задает отрицательный модус оценки, а дальнейший текст представляет собой аргументацию, объяснение существующего положения дел.

Статья начинается с абзаца:

Mine - perhaps, ours - is the first American generation that has yet to experience a full-blown, machine-gun shooting, prisoner-taking, horror-story war.
Онтологизация концепта WAR происходит в контексте сомнений, критики, осуждения, протеста, который соответствует интенциональным состояниям автора дискурса, формирующим, в свою очередь, единый горизонт восприятия текста. Комментарии характеризуются ярко выраженной точкой зрения автора на проблему и происходящие события.

Автор выделяет поколение американцев, рожденных в 60-х гг., которое знает о войне только по рассказам своих дедов, полагаясь, таким образом, на большую роль коллективного опыта, предшествующего коммуникации. Автор напоминает аудитории о том, чем является война на самом деле, и дифференцирует субъектов оценки по возрастному принципу:

We youngsters sit wide-eyed while our shaky grandfathers and crusty old uncles tell tales of enemy occupation, dead buddies, pretty gals and the joy of a fresh Lucky Strike on a quiet rainy afternoon.

В тексте создаются яркие образы, приводятся воспоминания и ассоциации, связанные с периодом оккупации. Старшему поколению приписываются следующие характеристики: shaky, crusty, old, молодому - wideeyed, что свидетельствует о различиях в интерпретации одного и того же контекста в силу несовпадения опыта.

Как отмечают психологи, одним из путей воздействия, в том числе манипуляции, является управление так называемым «психологическим пространством взаимодействия», которое складывается с момента установления контакта между коммуникантами. Как показано в лингвистических исследованиях, дихотомически противопоставленные концепты «свой» - «чужой» позволяют установить отношения между адресантом и адресатами (см., например [Иссерс, 2006, c. 202]). В анализируемом тексте автор обращается к определенному кругу американцев, выделяя свою целевую аудиторию, осуществляет самопрезентацию, очерчивая «свой круг», но, не разграничивая «своих / наших» и «чужих», а называя только «своих». Создание семиосферы «своего круга» в исследуемом дискурсе осуществляется косвенно, через имплицитные компоненты выс- 
казывания, в которых содержится намек на принадлежность к конкретной социальной группе, а именно к поколению американцев, родившихся после Вьетнама, местоимения множественного числа создают эффект общей сопричастности происходящему.

Автор дискурса считает, что носители североамериканской культуры не обладают достаточным военным опытом, поэтому не имеют морального права употреблять военные термины в немилитарных сферах, и эксплицирует этим явно негативное отношение к метафоризации в терминах войны, опровергая такие когнитивные метафоры, как POLITICS IS WAR, BUSINESS IS WAR (см.: [Lakoff]). Иллокутивной целью речевых действий автора является осуждение:

...my generation has not lived through skirmishes, conflicts and appalling battles. To those born in 1960s and beyond, Nazis are nothing but cultural extremists, Vietnam makes a good setting for a summer blockbuster, and a battle of Bulge is a Corny baby boomer punch line?

...the realities of the nation's major wars have been lost on one - going on two and three generations of Americans.

Those who grew up after Vietnam simply cannot comprehend the dread that shaped older generations ofAmericans.

Более того, по мнению автора, недостаток военного опыта и серьезного отношения к войне в буквальном смысле привел к «бездумному» употреблению военной лексики в повседневном общении. Об этом свидетельствует ряд следующих высказываний:

Since many of us have not experienced the sights and sounds of war firsthand, we think about war rather thoughtlessly.

Indeed, in our dearth of wartime experience, we have learned to deploy the images of war casually.

As war became less messy and more distant, the language of war invaded the common lexicon of America. Though you may have never noticed it, the extra-ordinary metaphor of war has infiltrated the everyday.

В тексте представлены следующие характеристики современных войн: less messy, more distant, acutely sterile.
Далее автор приводит примеры использования военных метафор в заголовках американских СМИ: Mayor Defends New Budget; Media Blitz saves Kidnapped Girl; Farmers Battle Summer Drought; War Heats Up; Champ's Left Hook Right on Target. Современный дискурс СМИ подтверждает справедливость суждений автора статьи: печатные издания политического, экономического и даже развлекательного характера содержат большое количество заголовков, так или иначе отсылающих читателя к феномену войны; обилие военных терминов свидетельствует о милитаризации североамериканцев и вербализации этого феномена.

5.2. В фокусе статьи «It is Time to Clean Up the War Vocabulary in sports», написанной Д. Андерсоном (см.: Anderson) в жанре открытого письма, в котором дан комментарий на публикацию К. Кауфмана (King Kaufman), автора спортивной колонки "New York Times", находится слово war, непосредственно соотносящее действия и события в мире спорта с действиями и событиями на поле боя. Хотя для американцев спорт - сфера, традиционно актуализируемая в военных терминах, основным коммуникативным намерением автора является привлечение внимания реципиентов на неоправданное в свете произошедших в стране трагических событий изобилие военной лексики в этой мирной сфере деятельности. Идея о том, что пора «очистить» язык спорта от военных терминов, прослеживается на протяжении всего текста. Приведем лишь небольшой его фрагмент:

Over the years, war and it's components have become part of sports' vocabulary. More than any sport, football has polished its popularity with the words of war that are now ingrained in the game's language.

Автор критикует конвенциональную метафорическую модель сравнения сценария войны со сценарием игры: It's not anywhere the same thing. There is no comparison. Основная макропропозиция, эксплицируемая автором, может быть сформулирована как «sport isn't (like) war» и свидетельствует о реализации протестной метафоры SPORT IS NOT WAR, структурирующей понимание данной ситуации, что иллюстрируют следующие утверждения: 
game is not like war; playing golf is not like walking through the minefield; athlete (a determined and successful competitor) is not a warrior; shorthanded specialists are not "penalty killers"; the long pass is not a "bomb".

В статье автор подробно описывает понятие мужества. Согласно словарям, содержание знака courage заключено в дефиниции - «the power or quality of dealing with or facing danger, fear, pain, etc». Этот знак восходит к архетипу мужества, хотя имя war отсутствует в дефиниции, однако имена danger, fear, pain входят в ассоциативное поле WAR. $\mathrm{C}$ целью определения ассоциативного пространства концепта ранее был применен метод ассоциативного эксперимента, в котором приняли участие 110 представителей разных возрастных и социальных слоев, проживающих в разных штатах США. Анализ ассоциативных связей слова war, а также базовых лексем-репрезентантов концепта WAR дал возможность обнаружить специфическую внутреннюю структуру концепта [Ухова, 2006, c. 114]. Д. Андерсон считает неоправданным сравнение мужества, отваги, бесстрашия, проявленных на войне и в спорте:

no sport demands the courage war does, no athlete - pro, college, high school, sandlot or playground - is being shot at, or wearing gas mask, or up there in a jet that's the target of antiaircraft fire no athletes... ever have been recommended for the Medal of Honor or even a combat ribbon.

В подтверждение мысли журналиста следует заметить, что в античном философском понимании мужество - это благодетель, непосредственно связанная с исполнением воинского долга [Платон, 1986, с. 243]. Мужество - архетипический компонент сценария войны.

5.3. Статья «Sports metaphors trivialize war» Р. Липсайта, журналиста и автора романа «Warrior Angel», изобилует примерами онтологизации концепта WAR, соотносящими военную и спортивную деятельность (см.: Lipsyte). Приведем один из них:

Ever since $9 / 11$, the customary practice of describing sports events in the language of war has seemed particularly repulsive. Nevertheless, sportscasters still have teams "blitzing" and "throwing bombs, " and games still end in "sudden death." Just part of the hype, I thought - obnoxious but probably harmless.

В анализируемой статье, в отличие от статей, рассмотренных выше, где дискурсообразующей являлась протестная метафора SPORT IS NOT WAR, концептуализация действительности осуществляется в соответствии с инвертированной метафорой WAR IS NOT SPORT: автор выносит на обсуждение проблему использования спортивной лексики в контексте реальной войны в Ираке, дескрипция ужасов которой происходит в терминах, применяемых в футболе:

How could the deadly decision to switch from "shock and awe" to the surgical "decapitation" of Saddam Hussein be depicted in the breezy jock jargon of a quarterback changing an offensive play at the last minute? Was I being a little too sensitive here?

Согласно Й. Хейзинге, определенные занятия, вызванные материальным интересом, никак не проявляющиеся в игровых формах, приобретают затем некие вторичные качества, которые трудно не назвать игровыми. Спорт - это игра, все более жесткая в своей растущей серьезности, но при этом все же остающаяся игрой; война - это серьезное занятие, перерождающееся в игру, но продолжающее считаться серьезным. Эти феномены (спорт и война) объединяет сильное агональное чувство участников событий, которое по-прежнему правит миром, хотя и в иных формах, чем ранее [Хейзинга, 2003, с. 197]. Ученый объясняет причины проникновения военной лексики в спортивный дискурс и наоборот, что подтверждает схожесть сценариев военных и спортивных событий. Учитывая приведенные выше значения существительного war, прототипическую конфигурацию соответствующего концепта можно представить следующим образом: война - акт агрессии, противоборства, соревнование, вторжение на чужую территорию. Такая конфигурация совпадает, в частности, со сценарием спортивной игры, например футбольного матча, который разворачивается по следующему плану: подготовка, разработка стратегии - вторжение на территорию противника - жесткое и агрессивное противостояние - нанесение удара - победа / поражение. 
6

Итак, исходя из проанализированного материала, можно сделать вывод о том, что, хотя сценарии войны и спорта весьма близки, концептуализация проходит в направлении «соревнование не есть война». Дискурс содержит прямой протест против нивелирования сущности понятия войны и драматизации спортивного дискурса в контексте времени культуры «After 9/11».

Ключевым событием, давшим импульс протестной знаковой деятельности, стали террористические акты $9 / 11$; восприятие дискурса идет по пути участия «протестующих» журналистов в групповой категоризации; дискурс характеризуется общей интенциональностью социума, направленной на борьбу со «злом» - терроризмом, на отмщение. Интенциональность текста как семиотического пространства может быть охарактеризована как направленность сознания на источник зла, коим является язык; совокупная метафорическая пропозиция текста реализуется в виде протестных метафор SPORT IS NOT WAR, WORDS ARE NOT WEAPONS, LANGUAGE IS NOT BATTLEFIELD, WAR IS NOT SPORT. Таким образом, трансформация отношения к концепту WAR в новом времени культуры «After 9/11» происходит через онтологизацию протестных метафор типа SOMETHING IS NOT WAR (SPORT IS NOT WAR, POLITICS IS NOT WAR, BUSINESS IS NOT WAR, etc.). Перечисленные протестные метафоры могут стать объектами дальнейшего лингвокультурологического исследования.

\section{ПРИМЕЧАНИЕ}

${ }^{1}$ Для проведения дефиниционного анализа использовались следующие лексикографические издания:

Cambridge Advanced Learner's Dictionary. Electronic text data. - Mode of access: http://www. yourDictionary.com. - Title from screen.

Cambridge International Dictionary of English. Cambridge : Cambridge University Press, 1995. $1772 \mathrm{p}$.

George Grabb, A. M. English Synonyms explained in alphabetical order / A. M. George Grabb. - London : G. Routledge and sons, 1902. -652 p.
Longman Dictionary of Contemporary English : in 2 vols. - Moscow : Longman, 1992. - 1229 p.

Longman Grammar of Spoken and Written English / D. Biber, S. Johansson, G. Leech [et al.]. Harlow, Essex : Longman, 1999. - 1204 p.

Macmillan English Dictionary for Advanced Learners. $-2^{\text {nd }}$ edition, int. stud. ed with CD-ROM, A\&C Black Publishers Ltd., 2007. - 1748 p.

The American Dictionary of the English Language : new ed. in celebration of Noah Webster's Birthday, 2009. - Electronic text data. - Mode of access: http://www.1828-dictionary.com. - Title from screen.

The American Heritage Dictionary of the English language. $-4^{\text {th }}$ ed. - Houghfon Miffin Co., 2000. Electronic text data. - Mode of access: http://www. yourDictionary.com. - Title from screen.

The Collin's Concise Dictionary of the English Language / ed. by P. Hanks. - London : Collins, 1988. $1392 \mathrm{p}$.

The Concise Oxford Dictionary. - Oxford : Oxford University Press, 1989. - 1264 p.

The Concise Oxford Dictionary of English Etymology / ed. by T. F. Hoad. - Oxford : Oxford University Press, 2003. - 1558 p.

\section{СПИСОК ЛИТЕРАТУРЫ}

Иссерс, О. С. Коммуникативные стратегии и тактики речевого воздействия / О. С. Иссерс. - Изд. 4-е, стер. - М. : КомКнига, 2006. - 288 с.

Каплуненко, А. М. Концепт - Понятие - Термин: эволюция семиотических сущностей в контексте дискурсивной практики / А. М. Каплуненко // Азиатско-Тихоокеанский регион: диалог языков и культур : сб. науч. док. Междунар. конф. - Иркутск : ИГЛУ, 2007. - С. 115-120.

Карасик, В. И. Лингвокультурный концепт как единица исследования / В. И. Карасик, Г. Г. Слышкин // Методологические проблемы когнитивной лингвистики. - Волгоград : ВГПУ, 2005. - С. 75-79.

Карасик, В. И. Языковой круг: личность, концепты, дискурс / В. И. Карасик. - Волгоград : Перемена, 2002. $-477 \mathrm{c}$.

Корнилов, О. А. Языковые картины мира как производные национальных менталитетов / О. А. Корнилов. - Изд. 2-е, испр. и доп. - М. : ЧеРо, 2003. - 349 с.

Лотман, Ю. М. Внутри мыслящих миров. Человек - текст - семиосфера - история / Ю. М. Лотман. - М. : Языки русской культуры, 1999. - 464 с.

Лотман, Ю. М. Культура и взрыв / Ю. М. Лотман // Семиосфера. - СПб. : Искусство-СПБ, 2000. C. $250-334$.

Малинович, Ю. М. Антропологическая лингвистика как интегральная наука / Ю. М. Малинович, М. В. Малинович // Антропологическая линг- 
вистика: Концепты. Категории : коллектив. моногр. ; под ред. и общ. науч. рук. д-ра филол. наук, проф. Ю. М. Малиновича. - Москва ; Иркутск : ИГЛУ, 2003. - C. 4-28 $547 \mathrm{c}$

Платон. Диалоги / Платон. - М. : Наука, 1986. -

Плотникова, С. Н. Дискурсивная стилистика жанра: анализ статей, выражающих мнение / С. Н. Плотникова // Проблемы стилистики и прагматики высказывания и текста : межвуз. сб. науч. тр. - Иркутск : ИГЛУ, 1997. - С. 96-105.

Почепцов, Г. Г. Языковая ментальность: способ представления мира / Г. Г. Почепцов // Вопросы языкознания. - 1990. - № 6. - С. 110-122.

Уткин, А. И. Единственная сверхдержава / А. И. Уткин. - М. : Алгоритм, 2003. - 576 с.

Ухова, Т. В. Ассоциативный эксперимент как один из способов выявления специфики отражения WAR в обыденном сознании североамериканцев / Т. В. Ухова // Развитие межкультурной компетенции через изучение иностранных языков: потенциал, методы, проблемы : материалы Междунар. сем. (Иркутск, 23-26 окт. 2006 г.). - Иркутск : ИГЛУ, 2006. - С. 114-116.

Ухова, Т. В. К вопросу исследования архетипичных концептов культуры: мифологические основания идеи войны / Т. В. Ухова // Современные тенденции в преподавании иностранных языков в неязыковом ВУЗе: материалы IV Регион. заоч. науч.практ. конф. (Красноярск, июнь 2010 г.). - Красноярск : СибГАУ, 2010. - С. 135-141.

Хейзинга, Й. Homo Ludens. Статьи по истории культуры / Й. Хейзинга. - М. : Айрис-Пресс, 2003. - 496 c.

Dijk, T. A. van. Handbook of Discourse analysis: Dimensions of Dicourse analysis / T. A. van Dijk. London : Academic Press, Inc., 1985. - Vol. 2. - 273 p.

Lakoff, G. Metaphor and War: The Metaphor System Used to Justify War in the Gulf / G. Lakoff. Electronic text data. - Mode of access: https:// georgelakoff.files.wordpress.com/2011/04/metaphorand-war-the-metaphor-system-used-to-justify-war-inthe-gulf-lakoff-1991.pdf. - Title from screen.

Swales, J. M. Genre Analysis / J. M. Swales. Cambridge : Cambridge University Press, 1990. $386 \mathrm{p}$.

\section{ИСТОЧНИКИ}

Anderson-Anderson, D. It is Time to Clean Up the War Vocabulary in sports / D. Anderson. Electronic text data. - Mode of access: http://www. nytimes.com/2003/03/23/sports/sports-of-the-times-its-time-to-clean-up-the-war-vocabulary-in-sports.html. Title from screen.
Hooten - Hooten, J. Fighting words: The war over language / J. Hooten. - Electronic text data. Mode of access: https://www.mail-archive.com/ ctrl@listserv.aol.com/msg103918.html. - Title from screen.

Lipsyte - Lipsyte, R. Sports metaphors trivialize war / R. Lipsyte. - Electronic text data. - Mode of access: http://usatoday30.usatoday.com/news/ opinion/editorials/2003-04-06-lipsyte x.htm. - Title from screen.

\section{REFERENCES}

Issers O.S. Kommunikativnye strategii i taktiki rechevogo vozdeystviya [Communicative Strategies and Tactics of Speech Influence]. Moscow, KomKniga Publ., 2006. 288 p.

Kaplunenko A.M. Kontsept - Ponyatie - Termin: evolyutsiya semioticheskikh sushchnostey v kontekste diskursivnoy praktiki [Concept - Notion - Term: Evolution of Semiotic Entities in the Context of Discourse Practices]. Aziatsko-Tikhookeanskiy region: dialog yazykov i kultur: sb. nauch. dok. Mezhdunar. konf. [Asian-Pacific Area: Dialogue of Languages and Cultures. Proceedings of Academic International Conference]. Irkutsk, IGLU Publ., 2007, pp. 115-120.

Karasik V.I., Slyshkin G.G. Lingvokulturnyy kontsept kak edinitsa issledovaniya [Linguacultural Concept as a Research Unit]. Metodologicheskie problemy [Methodological Problems]. Volgograd, VGPU Publ., 2005, pp. 75-79.

Karasik V.I. Yazykovoy krug: lichnost, kontsepty, diskurs [Language Circle: Personality, Concepts, Discourse]. Volgograd, Peremena Publ., 2002. 477 p.

Kornilov O.A. Yazykovye kartiny mira kak proizvodnye natsionalnykh mentalitetov [Linguistic Pictures of the World as Derivatives of National Mentalities]. Moscow, CheRo Publ., 2003. 349 p.

Lotman Yu.M. Vnutri myslyashchikh mirov. Chelovek - tekst - semiosfera - istoriya [Inside Thinking Worlds. Human-Text-Semiosphere-History]. Moscow, Yazyki russkoy kultury Publ., 1999. 447 p.

Lotman Yu. M. Kultura i vzryv [Culture and Explosion]. Semiosfera [Semiotic Sphere]. Saint Petersburg, Iskusstvo Publ., 2000, pp. 250-334.

Malinovich Yu.M., Malinovich M.V. Antropologicheskaya lingvistika kak integralnaya nauka [Anthropological Linguistics as an Integral Science]. Malinovich Yu.M., ed. Antropologicheskaya lingvistika: Kontsepty. Kategorii: kollektiv. monogr. [Anthropological Linguistics: Concepts, Categories. Collective Monograph]. Moscow; Irkutsk, IGLUPubl., 2003, pp. 7-28.

Platon. Dialogi [Dialogues]. Moscow, Nauka Publ., 1986. 547 p. 
Plotnikova S.N. Diskursivnaya stilistika zhanra: analiz statey, vyrazhayushchikh mnenie [Discourse Stylistics of Genre: Analysis of Articles Expressing Opinions]. Problemy stilistiki i pragmatiki vyskazyvaniya i teksta: mezhvuz. sb. nauch. tr. [Problems of Stylistics and Pragmatics of Utterances and Texts: Interuniversity Collection of Scientific Works]. Irkutsk, IGLU Publ., 1997, pp. 96-105.

Pocheptsov G.G. Yazykovaya mentalnost: sposob predstavleniya mira [Language Mentality: a Worldview]. Voprosy yazykoznaniya [Topics in the Study of Language], 1990, no. 6, pp. 110-122.

Utkin A.I. Edinstvennaya sverkhderzhava [The Only Superpower]. Moscow, Algoritm Publ., 2003. 576 p.

Ukhova T.V. Assotsiativnyy eksperiment kak odin iz sposobov vyyavleniya spetsifiki otrazheniya WAR v obydennom soznanii severoamerikantsev [Associative Experiment as One of the Ways of Revealing Specificity of WAR Reflection in the Conciousness of Northern Americans]. Razvitie mezhkulturnoy kompetentsii cherez izuchenie inostrannykh yazykov: potentsial, metody, problemy: materialy Mezhdunar. sem. (Irkutsk, 23-26 okt. 2006 g.) [Development of Intercultural Competence through the Study of Foreign Languages: Potential, Methods, Problems: Proceedings of the International Seminar (Irkutsk, October 23-26, 2006)]. Irkutsk, IGLUPubl., 2006. 156 p.

Ukhova T.V. K voprosu issledovaniya arkhetipichnykh kontseptov kultury: mifologicheskie osnovaniya idei voyny [On the Study of Archetypal Concepts of Culture: the Mythological Foundations of the Idea of War]. Sovremennye tendentsii $v$ prepodavanii inostrannykh yazykov $v$ neyazykovom
VUZe: materialy IV Region. zaoch. nauch.-prakt. konf. (Krasnoyarsk, iyun 2010 g.) [Modern Trends in Teaching Foreign Languages in Non-Linguistic University: Proceedings of the $4^{\text {th }}$ Regional Extramural Research Conference (Krasnoyarsk, June 2010)]. Krasnoyarsk, SibGAU Publ., 2010, pp. 135-141.

Kheyzinga Y. Homo Ludens. Statyi po istorii kultury [Homo Ludens: Articles on Culture History]. Moscow, Airis Press, 2003. 496 p.

Dijk T.A. van. Handbook of Discourse analysis: Dimensions of Dicourse analysis. London, Academic Press, Inc., 1985, vol. 2. 273 p.

Lakoff G. Metaphor and War: The Metaphor System Used to Justify War in the Gulf. URL: https:// georgelakoff.files.wordpress.com/2011/04/metaphorand-war-the-metaphor-system-used-to-justify-war-inthe-gulf-lakoff-1991.pdf.

Swales J.M. Genre Analysis. Cambridge, Cambridge University Press, 1990. 386 p.

\section{SOURCES}

Anderson D. It is Time to Clean Up the War Vocabulary in sports. URL: http://www.nytimes.com/ 2003/03/23/sports/sports-of-the-times-it-s-time-toclean-up-the-war-vocabulary-in-sports.html.

Hooten J. Fighting words: The war over language. URL: https:/www.mail-archive.com/ ctrl@listserv.aol.com/msg103918.html.

Lipsyte R. Sports metaphors trivialize war. URL: http://usatoday30.usatoday.com/news/opinion/ editorials/2003-04-06-lipsyte_x.htm.

\section{Information about the Authors}

Tatyana V. Ukhova, Assistant Professor, Department of Linguistics and Crosscultural Communication, Siberian State University of Science and Techlogies, Prosp. Krasnoyarskiy rabochiy, 31,660037 Krasnoyarsk, Russian Federation, ukhovta@yandex.ru, http://orcid.org/0000-0002-2949-3043

Svetlana G. Efa, Assistant Professor, Department of Linguistics and Crosscultural Communication, Siberian State University of Science and Techlogies, Prosp. Krasnoyarskiy rabochiy, 31, 660037 Krasnoyarsk, Russian Federation, limk2017@mail.ru, http://orcid.org/0000-0002-5175-3446

\section{Информация об авторах}

Татьяна Витальевна Ухова, старший преподаватель кафедры лингвистики и межкультурной коммуникации, Сибирский государственный университет науки и технологий имени академика М.Ф. Решетнева, просп. им. газ. «Красноярский рабочий», 31, 660037 г. Красноярск, Российская Федерация, ukhovta@yandex.ru, http://orcid.org/0000-0002-2949-3043

Светлана Георгиевна Эфа, старший преподаватель кафедры лингвистики и межкультурной коммуникации, Сибирский государственный университет науки и технологий имени академика М.Ф. Решетнева, просп. им. газ. «Красноярский рабочий», 31, 660037 г. Красноярск, Российская Федерация, limk2017@mail.ru, http://orcid.org/0000-0002-5175-3446 